\title{
Self-Service Technologies: Understanding Customer Satisfaction with Technology-Based Service Encounters
}

Self-service technologies (SSTs) are increasingly changing the way customers interact with firms to create service outcomes. Given that the emphasis in the academic literature has focused almost exclusively on the interpersonal dynamics of service encounters, there is much to be learned about customer interactions with technology-based self-service delivery options. In this research, the authors describe the results of a critical incident study based on more than 800 incidents involving SSTs solicited from customers through a Web-based survey. The authors categorize these incidents to discern the sources of satisfaction and dissatisfaction with SSTs. The authors present a discussion of the resulting critical incident categories and their relationship to customer attributions, complaining behavior, word of mouth, and repeat purchase intentions, which is followed by implications for managers and researchers.

$\mathbf{T}$ oday's fast-paced world is becoming increasingly characterized by technology-facilitated transactions. Growing numbers of customers interact with technology to create service outcomes instead of interacting with a service firm employee. Self-service technologies (SSTs) are technological interfaces that enable customers to produce a service independent of direct service employee involvement. Examples of SSTs include automated teller machines (ATMs), automated hotel checkout, banking by telephone, and services over the Internet, such as Federal Express package tracking and online brokerage services.

Although extensive academic research has explored the characteristics and dynamics of interpersonal interactions between service providers and customers (Bettencourt and Gwinner 1996; Bitner, Booms, and Tetreault 1990; Clemmer and Schneider 1996; Fischer, Gainer, and Bristor 1997; Goodwin 1996; Goodwin and Gremler 1996; Hartline and Ferrell 1996; Rafaeli 1993), much less research has investigated customer interactions with technological interfaces (Bitner, Brown, and Meuter 2000; Dabholkar 1996). The continuing proliferation of SSTs conveys the need for research that extends beyond the interpersonal dynamics of

\footnotetext{
Matthew L. Meuter is Assistant Professor of Marketing, Villanova University. Amy L. Ostrom and Robert I. Roundtree are Assistant Professors of Marketing, and Mary Jo Bitner is AT\&T Professor of Services Marketing and Management, Arizona State University. Each author contributed equally to the manuscript. The authors thank the three anonymous $J M$ reviewers for their insightful comments on previous drafts of the article. The authors also gratefully acknowledge the Center for Services Marketing and Management at Arizona State University for its support, as well as Greenfield Online, a division of the Greenfield Consulting Group, Westport, CT, for assistance in data collection.
}

service encounters into this technology-oriented context. This need is illustrated in many ways: For example, almost half of all retail banking transactions are now conducted without the assistance of a bank teller (Lawrence and Karr 1996). In addition, although some SSTs have become commonplace (e.g., ATMs, pay-at-the-pump terminals), more innovative SSTs continue to be introduced. For example, the Internet enables shoppers to purchase a wide variety of products without having to visit a retail outlet or converse with a service employee. In some states, users can file for divorce or evict a tenant using an automated kiosk rather than go through the traditional court system. Electronic selfordering is currently being developed by fast-food restaurants, and self-scanning at retail stores has been tested and is projected to become widely available in the future (Dabholkar 1996; Gibson 1999; Merrill 1999).

It is increasingly evident that these technological innovations and advances will continue to be a critical component of customer-firm interactions. These technologybased interactions are expected to become a key criterion for long-term business success. Parasuraman (1996) lists the growing importance of self-service as a fundamental shift in the nature of services. Although many academic researchers have acknowledged a need for greater understanding in this area (Dabholkar 1994, 1996; Fisk, Brown, and Bitner 1993; Meuter and Bitner 1998; Schneider and Bowen 1995), little is known about how interactions with these technological options affect customer evaluations and behavior. To further our understanding, we explored service encounters involving SSTs to identify sources of satisfaction and dissatisfaction. The research questions driving this study are as follows:

-What are the sources of customer satisfaction and dissatisfaction in encounters involving SSTs? 
-Are the sources of customer satisfaction and dissatisfaction with SST encounters similar to or different from the sources of customer satisfaction and dissatisfaction with interpersonal encounters?

-How are satisfying and dissatisfying encounters with SSTs related to attributions, complaining, word of mouth, and repurchase intentions?

To investigate these questions, we combined the critical incident technique (CIT) originally developed by Flanagan (1954) with quantitative measures of attributions, complaining behavior, word of mouth, and repurchase intentions. The critical incident method has been used in a wide variety of disciplines (e.g., Copas 1984; Lathan and Saari 1984; White and Locke 1981), including marketing (Bitner, Booms, and Mohr 1994; Bitner, Booms, and Tetreault 1990; Grove and Fisk 1997; Iacobucci, Ostrom, and Grayson 1995; Keaveney 1995). In this study, we use CIT to determine the sources of satisfaction and dissatisfaction with SSTs from the customer's point of view.

\section{Conceptual Foundations}

\section{Service Encounters}

Historically, virtually all service encounters took place with an employee and a customer present. Because of this, most service encounter research has focused on interpersonal interactions, mainly between customers and firm employees (Bitner, Booms, and Tetreault 1990; Mohr and Bitner 1995; Price, Arnould, and Deibler 1995; Solomon et al. 1985; Surprenant and Solomon 1987). For example, Solomon and colleagues (1985) explore personalization in the dyadic interaction between service providers and customers and the resulting customer satisfaction with the service. Researchers have also explored customer-customer interactions in service settings (Grove and Fisk 1997; Martin and Pranter 1989). Others have examined interpersonal dynamics in the context of service recovery encounters and the resulting impact on satisfaction (Smith and Bolton 1998; Tax and Brown 1998; Tax, Brown, and Chandrashekaran 1998).

Prior research has used CIT to examine sources of dis/satisfactory evaluations in interpersonal service encounters. Bitner, Booms, and Tetreault (1990) explore customer-employee interactions in restaurants, hotels, and airlines. They find that the factors affecting the evaluation of the service encounter can be classified into three main categories: (1) employee response to service delivery failure, (2) employee response to customer needs and requests, and (3) unprompted and unsolicited actions by employees. Grove and Fisk (1997) also use CIT to examine factors leading to dis/satisfactory evaluations of interpersonal service encounters. The focus of Grove and Fisk's study is customer-customer interactions in amusement theme parks. They find that service experiences were affected by other customers' adherence to implicit or explicit rules of conduct and by the perceived sociability of other customers.

Note that in each study, the set of factors that leads to satisfying encounters also leads to dissatisfying ones. In other words, the incident categories for satisfactory and dissatisfactory encounters were mirror images of each other. For example, in Bitner, Booms, and Tetreault's (1990) study, employee response to customer needs and requests was a source of both dissatisfaction and satisfaction, depending on the nature of the employee response.

Whereas these studies explore important determinants of dis/satisfaction in an interpersonal setting, we investigate factors that are important when a customer independently produces a service through a technological interface. This enables us to assess whether the sources of dis/satisfaction in interpersonal encounters are also important in technology-based encounters. In addition, we can determine if the same set of factors leads to both satisfactory and dissatisfactory encounters.

\section{Self-Service Technologies}

Recently, academic researchers have recognized the critical importance of technology in the delivery of services (Bitner, Brown, and Meuter 2000; Dabholkar 1994, 1996; Parasuraman 1996; Quinn 1996). Some suggest that the traditional marketplace interaction is being replaced by a marketspace transaction (Rayport and Sviokla 1994, 1995). The marketspace is defined as "a virtual realm where products and services exist as digital information and can be delivered through information based channels" (Rayport and Sviokla 1995, p. 14). The foundation of customer-company interactions has significantly changed in this new marketspace environment. Self-service technologies are a classic example of marketspace transactions in which no interpersonal contact is required between buyer and seller.

Several studies have investigated issues involving SSTs, mainly focusing on the development of user profiles (Bateson 1985; Darian 1987; Eastlick 1996; Greco and Fields 1991; Langeard et al. 1981; Zeithaml and Gilly 1987). For example, Langeard and colleagues (1981) attempt to segment markets on the basis of willingness to participate actively in the delivery of services. This is one of the most comprehensive early studies done to identify and describe customers who might be willing to use a self-service delivery alternative. Langeard and colleagues (1981) find that participators tend to be younger, single, and better educated and have a lower income level. Bateson (1985) explores the choice between a self-service option and an interpersonal service delivery system. Bateson examines the attractiveness of self-service options when the usual monetary or time-saving incentives are controlled and finds that a significant group of people choose to use a selfservice option even without monetary or time-saving benefits.

One issue to be noted from these early studies is that both Langeard and colleagues (1981) and Bateson (1985) make no distinction between technology-based self-service scenarios and more labor-intensive self-service situations. Only two of the six self-service scenarios used across the studies were technology-based (i.e., using ATMs and purchasing traveler's checks from an automated machine). It is likely that the technological aspect of many recent self-service options has a unique influence on consumer perceptions of these self-service encounters. Researchers continue to be interested in how attitudes toward technology may influence the extent to which consumers interact with technology-based products and services (Dabholkar 1996; Parasuraman 1998; Raub 1981). 
Dabholkar (1992) explores issues such as how attitudes toward computerized products and a need for interaction with service employees affect attitudes. Dabholkar finds that both factors influence consumer attitudes toward using a computerized fast-food ordering SST. In a more recent study, Dabholkar (1996) examines evaluations of SST service quality by making comparisons between an attribute model based on what customers expect from the computerized fast-food ordering SST across various attributes (expected speed of delivery, ease of use, reliability, enjoyment, and control) and an overall affect model based on beliefs about the use of technology and the need for interaction with service employees. Dabholkar finds the attribute model to be superior in predicting evaluations, and enjoyment and control are the two most influential attributes.

\section{Types of SSTS}

The existing research on SSTs focuses on either a single technology in a given study (e.g., Dabholkar 1992, 1996) or, in the case of the early studies, primarily low-technology self-service (e.g., hotel vending machines versus room service) and primitive forms of ATMs (Bateson 1985; Langeard et al. 1981). None of the research attempts to examine the range of SSTs available to consumers today. In the current study, we explore diverse available SSTs-some are well established, whereas others are in their infancy, and others may never be successful on a large scale.

In Figure 1 we present our conceptualization of presentday SST options, which is based on a review of the academic literature, trade press, observation, and our work with companies. The columns of the matrix represent the types of technologies companies are using to interface with customers in self-service encounters. The rows of the matrix represent the purposes of the technologies from the customer perspectivewhat the customer can accomplish by using the technology.

The types of technology interfaces (the columns in Figure 1) include telephone-based technologies and various interactive voice response systems, direct online connec- tions and Internet-based interfaces, interactive free-standing kiosks, and video or compact disc (CD) technologies. Sometimes these technologies are used in combination. For example, a company provides a CD that enables a customer to review products or services and then link directly to a Web site for more information or ordering. Similarly, a customer might buy a mail-order item through an automated telephone system but then track the delivery time for the package through a Web site that provides automated packagetracking capabilities.

Companies provide SSTs for a variety of purposes broadly captured by the rows in Figure 1. First, many forms of customer service are now provided through technology. Questions regarding accounts, bill paying, frequently asked questions, and delivery tracking are just a few examples of customer service that are now provided through SSTs. Some examples of excellence in this arena are FedEx's Internet-based package tracking, Cisco System's online troubleshooting, and Wells Fargo Bank's telephone- and Internet-based banking.

A second extremely rapidly growing arena for SSTs is direct transactions. The technology enables customers to order, buy, and exchange resources with companies without any direct interaction with their employees. Examples of outstanding SST transactions are Charles Schwab's online trading service, Amazon.com, and the SABRE Group's Travelocity, an Internet-based travel ticketing service. Recent studies cite rapid growth in Internet-based transactions for both consumer and business-to-business sales (Hof 1999).

The third use of SSTs is the broad category called selfhelp, which refers to technologies that enable customers to learn, receive information, train themselves, and provide their own services. Examples include health information Web sites, tax preparation CDs and software, self-help videos, and telephone-based information lines. In a business-to-business context, GE Medical Systems provides video and satellite-television-based "just-in-time training" on its equipment for hospital and clinic customers, which enables customers to train themselves at their convenience.

\section{FIGURE 1 \\ Categories and Examples of SSTs in Use}

\begin{tabular}{|c|c|c|c|c|}
\hline$P_{u_{r_{p} p_{S_{\mathrm{e}}}}}$ & $\begin{array}{c}\text { Telephone/Interactive } \\
\text { Voice Response }\end{array}$ & $\begin{array}{l}\text { Online/ } \\
\text { Internet }\end{array}$ & Interactive Kiosks & Video/CD* \\
\hline $\begin{array}{r}\text { Customer } \\
\text { Service }\end{array}$ & $\begin{array}{l}\text {-Telephone banking } \\
\text {-Flight information } \\
\text {-Order status }\end{array}$ & $\begin{array}{l}\text {-Package tracking } \\
\text {-Account information }\end{array}$ & $\begin{array}{l}\text {-ATMs } \\
\text { •Hotel checkout }\end{array}$ & \\
\hline Transactions & $\begin{array}{l}\text {-Telephone banking } \\
\text {-Prescription refills }\end{array}$ & $\begin{array}{l}\text {-Retail purchasing } \\
\text {-Financial transactions }\end{array}$ & $\begin{array}{l}\text {-Pay at the pump } \\
\text { - Hotel checkout } \\
\text {-Car rental }\end{array}$ & \\
\hline Self-Help & $\begin{array}{l}\text {-Information telephone } \\
\text { lines }\end{array}$ & $\begin{array}{l}\text {-Internet information } \\
\text { search } \\
\text {-Distance learning }\end{array}$ & $\begin{array}{l}\text {-Blood pressure machines } \\
\text {-Tourist information }\end{array}$ & $\begin{array}{l}\text {-Tax preparation } \\
\text { software } \\
\text {-Television/ } \\
\text { CD-based training }\end{array}$ \\
\hline
\end{tabular}

\footnotetext{
* Video/CD is typically linked to other technologies to provide customer service and transactions.
} 
Figure 1 provides examples of SSTs across the purposes and types of technology interfaces just described. Although the present-day excitement over Internet applications means that many companies are channeling their resources into that column of the matrix, it is apparent that a wide range of SST possibilities exists. In the research reported here, we explore all types of SSTs without attempting to compare and contrast specific cells within the matrix.

\section{Customer Responses to SST Encounters}

Given the proliferation of SSTs and the wide variety of types and purposes of these SSTs, it is critical to understand how customers feel about them, how they use them, and if they will use them in the future. This research represents a first step in this direction by exploring customer experiences across a broad range of SSTs available in the marketplace. The primary focus of this study is the sources of dis/satisfaction underlying SST experiences. It is well established that customer satisfaction can affect customer retention and profitability (Anderson and Fornell 1994; Mano and Oliver 1993; Oliver 1993, 1997; Price, Arnould, and Tierney 1995; Reichheld and Sasser 1990). Thus, understanding the underlying factors that trigger dis/satisfaction in SSTs has important managerial implications for customer-firm relationships.

We also explore customer attributions with respect to SST outcomes. Research has shown that customer evaluations are influenced by attributions for success and failure in interpersonal service situations (Bitner 1990; Folkes, Koletsky, and Graham 1987). With SSTs, customers create the service for themselves, so it is possible that they will accept more of the responsibility for the outcome (Mills, Chase, and Margulies 1983; Zeithaml 1981). If customers accept partial responsibility in dissatisfying situations, they may be more likely to use the SST in the future. Again, this could have important managerial implications as companies develop new SSTs and struggle with service encounter failures.

We examine important postencounter behaviors, such as complaining, word of mouth, and future intended behaviors. When a customer complains, the firm has the opportunity to rectify the situation and potentially create a more satisfied customer (Tax, Brown, and Chandrashekaran 1998). Complaints also provide information that can be used to fix service failure points. Yet how can customers complain effectively in SST situations? We also study the relationship between SST dis/satisfaction and future intentions such as repeat purchasing and word of mouth. How do these experiences affect future behaviors? Do customers plan to use the specific company or the SST again? Because so little has been published on SSTs, we explore these questions to further the understanding of the complexities surrounding customer interactions with SSTs.

\section{Method and Procedure}

\section{Critical Incident Technique}

We used CIT to investigate the sources of dis/satisfactory evaluations of SST interactions. ${ }^{1}$ This technique is a form of content analysis that involves the classification of stories or

\footnotetext{
${ }^{1}$ For a review of CIT, see Bitner, Booms, and Tetreault (1990), Grove and Fisk (1997), and Keaveney (1995).
}

critical incidents with the intent of uncovering emergent patterns or themes (Bitner, Booms, and Tetreault 1990). With CIT, respondents are asked not to identify the cause of their satisfaction or dissatisfaction but rather to describe a specific incident in as much detail as possible. Prior research indicates that people are adept at describing these types of stories (Bitner, Booms, and Tetreault 1990; Keaveney 1995). For this study, we focus on eliciting descriptions of memorable incidents about a recent SST interaction.

As a qualitative methodology, CIT is meant not to be generalizable but rather to provide insight into the nature of the phenomenon under investigation. Given this, most studies using CIT focus exclusively on the categories that emerge and the characteristics of those categories. Although CIT categories are rarely linked to any additional quantitative measures (for an exception, see Hoffman, Kelley, and Rotalsky 1995), in this research we incorporated a series of quantitative questions to gain a greater understanding of perceptions of the incident as well as subsequent behavior. These quantitative measures enable us to explore further the nature of the results and the perceptions and behavior of the respondents.

\section{Data Collection Procedure}

Because usage and experience with a wide range of SSTs is not yet a common phenomenon, a simple random sample of the population would likely result in a sample with limited SST experiences. The study described here requires sufficient experience with SSTs so respondents can draw on at least one memorable encounter and describe it in detail. In addition, we wanted a nationwide sample of respondents to avoid any geographic bias or differences in regional availability of SST options. Because of this, a specific nationwide audience that was expected to use a wide range of SSTs was targeted for data collection. The population consisted of a database of respondents from a marketing research firm that specialized in consumer surveys over the Internet. We presumed that this population would have substantially more experience with various SSTs than the general population. Although the sample may not be representative of the general U.S. population, it addresses the needs of this study. In addition, this sampling approach enabled us to collect critical incident stories from a nationwide sample of consumers in a timely and cost-effective manner.

The database comprises more than one million people who signed up and agreed to complete online surveys in exchange for cash prizes or other incentives. The survey instrument (to be described subsequently) was placed on a Web site, and e-mail messages were sent to members of the database notifying them of a new survey and requesting their participation. The survey notice was also placed in the firm's "open response" area, where any current member could complete the survey. A random drawing for ten $\$ 50.00$ cash prizes was held as an incentive to complete the survey. In less than two weeks, 1000 responses were collected electronically. The survey was then removed from the Web site, and the data were transferred to us for analysis.

Two concerns when an Internet-based survey is used include respondents filling out a survey multiple times and "random walk-ins" (i.e., people who are not part of the population of interest) finding the Web site and completing the 
survey. The participating marketing research firm avoids these problems by assigning each database member a unique password that is needed to complete a survey. Password protection prevents users from completing the survey multiple times and eliminates random walk-ins.

\section{Questionnaire Content}

The questionnaire began by asking respondents to indicate their current level of use for a wide range of SSTs available in the marketplace. The SSTs included in the survey were automated airline ticketing machines, automated hotel checkout, automated car rental machines, package tracking, tax preparation software, automated investment transactions, ATMs, automated telephone banking, other automated telephone services (e.g., for flight information), Internet shopping, general Internet information searches, automated gambling machines, electric blood pressure machines, and pay-at-thepump terminals. These SSTs were presented to familiarize respondents with the term "self-service technology" and provide several examples. The list was developed to reflect a cross-section of SSTs available in various industries with different technology-based delivery methods (e.g., telephonebased, computer-based). Respondents were then asked, on the basis of their experience with these or any other SST options they may have used, to "Think of a time when, as a customer, you had what stands out in your mind as either a particularly satisfying or dissatisfying experience with a self-service technology." To allow for a detailed incident description, respondents were free to select the SST and were not restricted to the examples provided. In addition, participants were able to choose whether they wanted to describe a satisfactory or dissatisfactory experience. The following questions were then asked to elicit a detailed description of the incident:

-Which self-service technology are you focusing on?

-Was this a satisfying or a dissatisfying experience?

-Please describe the circumstances leading up to this incident.

-Describe what happened during the incident. What specific details do you recall that made this experience memorable for you?

-What was the outcome of the incident?

-How could this experience have been improved (if at all)?

-Did you complain to the firm about this incident? If yes, how did you complain? If no, why not?

We asked additional questions to get a more complete understanding of the specific SST experience. We assessed customer attributions using a single-item measure adapted from Hubbert (1995). Whereas most attribution measures categorize the cause as either internal or external, this single-item measure allows for assessments of joint attributions. Respondents indicated whether they believed the outcome of the SST experience was due to the service firm or the technology, to their own actions, equally to both, or to neither. We also probed behavioral intentions pertaining to the SST. Measures of the likelihood of participating in word-of-mouth behavior and repeat purchase intentions were assessed through single-item measures for the type of SST in general, the specific company's SST, and the specific company. We assessed these measures with seven-point Likert scales.

\section{Data Analysis}

\section{Characteristics of the Sample}

A total of 1000 respondents completed the online questionnaire. We eliminated 177 responses because they either were vague and lacked descriptive detail or did not address an experience with a specific SST. This resulted in a final sample of 823 incidents-459 (56\%) describing satisfactory encounters and 364 (44\%) describing dissatisfactory encounters.

The sample of respondents was composed of slightly more women $(53 \%)$ than men $(47 \%)$. The largest group of respondents was between the ages of 25 and 34 years (32\%); however, those in the sample range from less than 18 to more than 64 years of age. In terms of education, $43 \%$ of the sample had an associate's degree or a more advanced college degree. The income distribution ranged from an annual income of less than $\$ 15,000$ (13\%) to $\$ 75,000$ or more $(15 \%)$. The most common income bracket represented was between $\$ 35,000$ and $\$ 50,000$ (22\%). Overall, the sample was slightly younger and had higher education and income levels than the general population. Note that though our sample may not be representative, the target population of online survey participants was purposely selected to meet the needs of this study discussed previously.

\section{Category Development and Reliability}

Three judges familiar with the topic of SSTs sorted the critical incident responses into categories and subcategories that reflected the sources of dis/satisfaction. Judges A and B developed a classification scheme that consisted of 13 mutually exclusive and exhaustive categories for the 823 incidents. Judges A and B then independently classified each of the critical incidents into the categories believed to derive customer dis/satisfaction with SSTs. All disagreements were resolved through discussions. Judge $\mathrm{C}$ then sorted the 823 responses on the basis of the categories developed by Judges A and B.

The interjudge reliability between Judge $C$ and Judges A and B (a two-way comparison) was calculated using the percentage agreement statistic. Interjudge reliability was $83 \%$ for the satisfying incidents and $85 \%$ for the dissatisfying incidents. These figures are respectably high, given that the resulting classification system in the study contains 13 categories. The percentage agreement statistic has been shown to underestimate interjudge reliability when there is a large number of categories (Perreault and Leigh 1989). Therefore, an alternate index of reliability, $\mathrm{I}_{\mathrm{r}}$, was calculated. In contrast to the percent agreement statistic, $I_{r}$ is based on a model of the level of agreement that might be found given a true (population) level of reliability (Perreault and Leigh 1989). Another benefit of this index is that it focuses on the reliability of the whole coding process, not only on the agreement between judges. Between Judge $C$ and Judges $A$ and $\mathrm{B}, \mathrm{I}_{\mathrm{r}}$ was .90 for both the satisfying and dissatisfying incidents.

\section{Results}

The most commonly described types of SSTs were ATMs, various Internet shopping services, pay-at-the-pump terminals, and various automated telephone services. Additional 
SSTs described in the study include automated hotel checkout, package tracking, automated car rental pickup and return, and online brokerage services, among others. The main objective of a critical incident study is the classification of incidents into meaningful categories. The distribution of incidents across categories developed by the judges is presented in Table 1 with illustrative quotes. Each category is described in more detail in the sections that follow. The sources of satisfactory evaluations are discussed first, followed by a description of the sources of dissatisfactory evaluations. In addition, results related to the quantitative measures are described.

\section{Satisfying Incident Categories²}

Group 1: solved intensified need. Of the satisfying incidents, $11 \%$ involved the SST solving an intensified need. Intensified needs are defined as situations in which external environmental factors add a sense of urgency to the transaction. Self-service technologies usually have wider availability and longer, more flexible hours of operation. Because of these characteristics, SSTs are often available to help customers immediately solve a problem. Satisfaction was driven by the SST's ability to bail customers out of a difficult situation or solve the acute problem they were experiencing. For example, one respondent said, "My son had just wrecked my car and I needed cash to get it towed. The banks were all closed, but I could get the money I needed in a hurry." In other incidents in this group, respondents detailed the nature of the problem they were facing (e.g., "I was low on gas in a really bad neighborhood and was scared.") and how the SST helped alleviate their concerns.

Group 2: better than the alternative. For many of the satisfying incidents (68\%), satisfaction with the SST was driven by the improvements or additional benefits provided by using the SST. In these incidents, customers perceived that the SST was a better alternative than the interpersonal method of service delivery. The group is made up of six subcategories, described subsequently, that highlight particular benefits that appear to lead to satisfying SST service encounters.

Group 2A: easy to use. For some of the encounters (16\%), that the SST was easy to use or easier to use than the interpersonal service option led to customer satisfaction. This category included incidents in which the SST was described as having simple or clear instructions or a straightforward process. For example, one respondent describing an ATM encounter said, "I put my card in and followed the easy instructions - got my cash, my card, and a receipt. The experience was memorable because it was easy."

Group 2B: avoid service personnel. Of the satisfying incidents, $3 \%$ involved respondents describing how the SST

\footnotetext{
${ }^{2}$ Seven satisfying incidents were categorized as miscellaneous because they did not fit into any of the emergent categories and no common themes were identified among them. These 7 incidents were subsequently dropped from the analysis, which left a final sample of 816 .
}

enabled them to perform the service without having to interact with anyone (e.g., "I really like being able to pay at the pump and avoid moronic salespeople.") In many of these cases, customers believed they could provide the service more effectively than firm employees. The benefit of using self-service was that they did not have to interact with service personnel to achieve the service outcome.

Group 2C: saved time. This is the largest of the six subcategories, making up $30 \%$ of the satisfying incidents. These incidents focused on the desired outcome following especially quickly after the transaction was performed. In addition, the SSTs have also been described as allowing the actual transaction to be performed more quickly or efficiently than does the interpersonal alternative. Examples include incidents in which users were able to get information more quickly from the Internet than if they had to wait for it to be mailed. Additional comments illustrating the category include "I didn't have to wait in line" and "I was in and out very quickly." A user of bank services commented, "The drive-up windows to the bank were five cars deep at each one. The ATM line was empty, so I finished my business quickly."

Group 2D: when I want. This group, corresponding to $8 \%$ of the satisfying incidents, includes incidents that focus on how the SST enabled the user to perform the service anytime, day or night (e.g., "I was able to use the Internet to track a scheduled flight. I felt in control being able to track the flight;" "While shopping for a new computer, I was able to research all the options and check pricing online within minutes. Best of all, it was 2 A.M.- the Internet is always open."). This usually was discussed as being important because of limited service hours offered by the firm, the respondent having a difficult work schedule, or other factors that cause the user to need the particular service on demand.

Group 2E: where I want. In $5 \%$ of the incidents, the SST enabled users to perform the service from off-site locations. Respondents appear pleased that they are not forced to travel to the service firm to consume a service. One respondent indicated, "I had left a large company with stocks from a $401 \mathrm{~K}$ plan. It seemed logical to be able to trade and make decisions from anywhere. I do not have to go to an office or out of my way to be able to handle my money." Many incidents in this category describe situations in which the SST enabled the user to obtain the service from home, from the office, on the road, or at other locales.

Group 2F: saved money. In $6 \%$ of the incidents, the SST enabled users to save money by helping them get a better deal. A user of automated ticketing stated, "I was able to buy a ticket for a cheaper fare through automated ticketing in comparison to calling a travel agent." Many firms offer financial incentives for consumers to use SSTs. These incidents include receiving various incentives for using SSTs, such as frequent flyer miles or other financial benefits.

Group 3: did its job. Satisfaction in the third major group of incidents revolved around the SST doing what it was intended to do. For many users (21\%), satisfaction results from the mere fascination with the capabilities of various SSTs and a sense of "Wow-it really works!" These incidents are descriptions of what the SST does when it is 
TABLE 1

Distribution of Incidents

Satisfying Incidents

Group Number and Name

Illustrative Quotes

Percentage

of Total

1. Solved intensified need

"My ride to work didn't show up, and I had no money in my pocket. I had

$11 \%$ 20 minutes to get to work. I went to the cash machine and got some cash for the cab ride.... I made it to work 10 minutes late instead of not at all."

2. Better than the alternative

$68 \%$

2A. Easy to use

"The page's forms were clear and easy to use. I had no difficulty deciding on

$16 \%$ my purchase and going ahead with the order." (regarding purchasing roses through the 1-800-FLOWERS Internet page)

2B. Avoid service personnel

"I like shopping on the Internet because there is no salesperson to bribe you."

2C. Saved time

"I was on my way to a friend's house and was low on gas. I was in a huge hurry, so using the pay at the pump saved me a lot of time."

$30 \%$

2D. When I want

"[I] was having a videotape of a house I was interested in putting an offer [on] and was very anxious to get the tape so I could make my decision. [It was] convenient to be able to check on [the] parcel's whereabouts any time of day or night."

2E. Where I want

"I can check out [library] books by phone without having to drive all the way down to the library to renew them."

$5 \%$

"I called around to several car agencies and was unable to get a price that was within my range. I decided to try Alamo online. I entered the information and came up with a price that was \$20 less per week than when I had called them."

3. Did its job

"I needed gas ...[, which involved] inserting the card, selecting credit, pumping the gas, and then asking for a receipt. I received the gas I needed and wanted, and got a receipt." service center at Disney with my order confirmation number. They had lost my order. I reordered, only to be sent the incorrect merchandise twice."

6. Poor design

6A. Technology design problem

6B. Service design problem

7. Customer-driven failure
"I was trying to order books from a book club online. The system was confusing, and I ordered two of the same title without knowing it."

"I did not realize that some (ATM) machines put limits on how much you can get out. The machine did not tell me I went over my limit for the day. It just spit my card back out so I kept trying different amounts until I was able to get some cash out."

"I was attempting to get money from an ATM and couldn't remember my [personal identification] number. I was leaving in one hour before the bank opened for mainland Japan, and the machine took my card."
$17 \%$

$19 \%$

$4 \%$ 
working properly (e.g., "I knew there was a Milwaukee, WI, cheese shop online. I found their site, saw the pictures, picked out what I wanted, entered the information, and clicked on submit. Seven or eight days later it arrived as expected."). Just having the SST do what it is supposed to do was enough to satisfy these users. For example, for some respondents, the fact that they could search for information on the Internet and find it, track their shipped packages online, check their bank account balances online or over the telephone, or check out of a hotel from their rooms is what made interacting with the SST a satisfying experience.

\section{Dissatisfying Incident Categories}

Group 4: technology failure. The largest group of dissatisfying encounters involved technical failures $(43 \%)$ due to the technology not working as intended. There was a breakdown of delivery at the point at which the customer interacts with the technology. Typical examples include a broken ATM or pay-at-the-pump machine. Another example comes from a user of Internet brokerage services, who stated, "I tried to trade in my brokerage account, but the system refused to log me on." These technology failures can be especially frustrating for customers who have come to rely on the ability to perform many of these transactions 24 hours a day from wherever they want.

Group 5: process failure. In these incidents (17\%), the SST functioned as designed, but there was a breakdown or failure in the process after the customer-technology interaction occurred. These failures were commonly related to post-SST interaction issues, such as billing, delivery, or processing of a transaction. An example is a respondent who never received a product after it was successfully ordered and paid for over the Internet. These incidents tended to focus on a mistake that would be unlikely to happen if the SST was used again in the future. For example, a telephone banking customer said his dissatisfaction resulted from "a wrong account number entered by the bank, causing [the] company to say I had not paid their bill." These failures can be disturbing, because the customer has no idea the transaction was not performed properly until later, when problems arise.

Group 6: poor design. Several incidents (36\%) dealt with problems involving the design of the service experience. These were aspects of the service built into the system such that any customer using the SST would be confronted with the same issue (though not all customers will perceive the design as dissatisfying). These incidents were further divided into two subcategories: technology design problems and service design problems.

Group 6A: technology design problem. This category is made up of $17 \%$ of the dissatisfactory incidents. In these cases, the SST was functioning as designed, but the technology performed in such a way that the user was unhappy with the encounter (e.g., "Hard to figure out how to log off the service. If it is not done properly, the next person who calls can get your account information."). Incidents in this category focused on problems such as Internet applications or automated telephone systems being too slow or having unclear directions and the user not being able to navigate the system or talk in person with a customer service representative.

Group 6B: service design problem. This category, consisting of $19 \%$ of the dissatisfying incidents, includes situations in which the SST interface functioned as planned but there was some other aspect of the design of the rest of the service that respondents did not like. In one incident, an online shopper said, "I was buying a present for a friend that lives far away. They would only deliver it to the cardholder address." Other respondents discussed incidents in which it took too long for money put into an ATM to be credited to their account, fees were charged for using the SST, or there were rules set by the service firm that limited how frequently the technology could be used. Contrary to the process failure category, these service design problems do not entail an actual breakdown or failure, because the transaction is processed according to the SST's design.

Group 7: customer-driven failure. In a small number of instances (4\%), customers seemed to acknowledge that the failure of the SST occurred, at least in part, because of their own actions (e.g., "With the assistance calls for some Internet providers, the categories seem the same. I needed help, so I called. I've misdialed the correct connection and had to call back."). Customers occasionally realize that their own actions may have contributed to the dissatisfactory outcome. Additional examples include a respondent who forgot his personal identification number, which made it impossible to complete an ATM transaction, and others who discussed how a demagnetized card prevented them from using the ATM.

\section{Consumer Reactions to the SST Experience}

Frequently, studies using CIT report and discuss only the qualitative categories that emerge from the data. By including a series of quantitative measures to elicit additional information related to the incident, we can link the qualitative categories to other consumer evaluations and behaviors. The following sections link measures of attributions, complaining, and future behaviors (such as repeat usage and word of mouth) with the qualitative categories developed previously. These quantitative measures and their relationship to the critical incident categories help us support and more fully develop the findings and conclusions drawn from the critical incident data. As discussed previously, because of the nonrandom nature of the data, the quantitative results are not intended to be generalizable; rather, the findings represent characteristics of this sample.

Attributions. We investigated attributions to determine if dis/satisfying incidents are related to differences in attributions for the outcome. A chi-square analysis was performed to examine the relationship between incident satisfaction level (satisfying versus dissatisfying) and the nature of the attribution made for the outcome (i.e., the outcome was due to the respondent, to the technology or service provider, equally to each, or to neither). We found a significant relationship between incident satisfaction level and the type of attribution $\left(\chi^{2}=72.36, p<.001\right)$.

Most respondents attributed the outcome to the technology $(63 \%)$. It is not surprising that customers recognize the critical role that technology plays in affecting service outcomes. Twenty-nine percent of all incidents were satisfying 
situations in which the positive outcome was attributed to the technology, whereas $34 \%$ of all incidents were dissatisfying situations in which the negative outcome was attributed to the technology. Although more respondents attributed the outcome to the technology for dissatisfactory than satisfactory encounters, this difference is only marginally significant $\left(\chi^{2}=3.3, p<.069\right)$. Respondents attributed a much smaller percentage of incident outcomes to themselves $(6 \%)$. More respondents attributed the outcome to themselves for satisfactory incidents (4\%) than dissatisfactory incidents $(2 \%)$. Again, although the results appear to indicate that respondents take credit for positive outcomes and assess blame for negative outcomes, the difference is only marginally significant $\left(\chi^{2}=3.0, p<.083\right)$.

Additional insight into consumer attributions comes from respondents who cited both themselves and technology as equally responsible for the outcome. Overall, $25 \%$ of the respondents attributed the outcome equally to themselves and the technology. Twenty percent were satisfying incidents in which respondents attributed the outcome to both equally, whereas only $5 \%$ were dissatisfying incidents $\left(\chi^{2}{ }_{1}=74.6\right.$, $p<.0001)$. This indicates that the respondents take credit for their role in creating positive outcomes yet assign blame elsewhere for dissatisfactory outcomes. A small percentage of the respondents $(6 \%)$ indicated that neither the technology nor themselves were responsible for the outcome. Three percent were satisfying incidents, and 3\% were dissatisfying incidents. Overall, the attribution findings indicate that respondents tend to blame the technology or the service provider more often when things go wrong (which may be reasonable given the large percentage of technology failures that were described) but tend to take at least some of the credit when the encounter is concluded in a satisfactory manner.

Complaining. Given the considerable interest in studying complaining behavior (Oliver 1997; Tax, Brown, and Chandrashekaran 1998), it is important to understand the extent and nature of complaining that occurs in the SST context. The relationship between incident satisfaction level and complaining behavior was examined, and a significant relationship between the two was found $\left(\chi^{2}{ }_{1}=254.1, p<.001\right)$. As would be expected, few satisfying incidents led to complaints $(\mathrm{n}=8)$. Satisfactory incident "complaints" are best described as suggestions for improving some aspect of the service rather than true complaints regarding the quality of the service that was provided. Of the dissatisfying incidents, $51 \%$ of the respondents subsequently complained. This is somewhat higher than other studies that examine complaining, in which the percentage of dissatisfied customers who complain is often $40 \%$ or less (Heskett, Sasser, and Schlesinger 1997; Technical Assistance Research Programs Institute 1986).

To explore this relatively high complaining rate, complaining behavior was examined across dissatisfactory categories. The relationship between complaining and the dissatisfying incident categories was found to be significant $\left(\chi^{2}=21.74, p<.001\right)$, which indicates that the level of complaining differs significantly depending on the source of dissatisfaction. Of the five dissatisfactory groups (technology failure, process failure, technology design, service design, and customer-driven failure), three exhibit complaining rates greater than $50 \%$. Of respondents describing incidents related to process failure, $68 \%$ indicated that they complained to the firm about their SST experiences. Fifty-five percent of the technology failure and $51 \%$ of the service design incidents also resulted in a complaint to the service firm. The other two groups generated fewer complaints. Only $30 \%$ of the respondents describing technology design incidents complained, whereas $25 \%$ of the respondents describing customer-driven failures complained.

Of the 188 respondents who complained about their SST experiences, $147(78 \%)$ specified how they communicated their dissatisfaction to the firm. Of those, $43 \%$ contacted a customer service representative by telephone, and $40 \%$ went to the service facility to discuss their displeasure. Twelve percent sent an e-mail message or complained through a Web page, and 5\% wrote a complaint letter.

Word-of-mouth and repurchase. A factor analysis of the word-of-mouth and repurchase intention items indicated that there was one factor composed of six items labeled future behaviors $(\alpha=.93){ }^{3}$ These items assess future behaviors (i.e., word of mouth, repurchase intentions) with respect to the company described in the encounter and the specific company's SST, as well as the word-of-mouth and repurchase intentions directed at the general type of SST described in the incident. For future behaviors, there was a main effect of incident satisfaction level $\left(\mathrm{F}_{1,794}=472.46\right.$, $p<.0001)$. Not surprisingly, respondents were more likely to engage in positive future behaviors for satisfying incidents $(\bar{X}=6.42)$ than for dissatisfying ones $(\bar{X}=4.21)$.

No differences were found in future behaviors across the satisfying incident categories $\left(\mathrm{F}_{7,436}=.35, p<.93\right)$. It appears that repurchase intentions and word-of-mouth behavior for these respondents are not affected by the reason an encounter was satisfying. However, future behavior may be influenced by what caused an encounter to be dissatisfying. There was a main effect across the dissatisfying categories $\left(\mathrm{F}_{4,348}=7.12\right.$, $p<.0001)$. Respondents were more likely to engage in positive future behaviors when there had been a technology failure $(\overline{\mathrm{X}}=4.62)$ or the failure was customer driven $(\overline{\mathrm{X}}=5.92)$ than when there was a process failure $(\overline{\mathrm{X}}=3.83$, both $p<.05)$, a technology design problem $\left(\overline{\mathrm{X}}=3.85 ; p_{\text {technology failure versus }}\right.$ technology design $<.06, p_{\text {customer-driven failure versus technology design }}<$ $.05)$, or a service design problem $(\overline{\mathrm{X}}=3.66$, both $p<.05)$.

\section{Discussion and Implications}

In the following section, we discuss our research findings as they relate to the three research questions guiding our investigation. In our discussion of each question, we also highlight the managerial implications of our results.

\section{Sources of Satisfaction or Dissatisfaction in SST Encounters}

Our primary goal in this research was to investigate the sources of dis/satisfaction with SSTs. Through the critical incident investigation, we found three major groups of fac-

${ }^{3}$ One of the word-of-mouth items was dropped because of poor loadings. 
tors leading to a satisfactory evaluation of an SST experience and four major groups of factors leading to a dissatisfactory evaluation of an SST experience.

The classification of the satisfying incidents indicates that for several of the incidents described, satisfaction is due to the SST's ability to bail customers out of immediate or troubling situations. Self-service technologies are ideally suited to handle many of these types of situations because of their pervasive nature and relatively easy accessibility. A readily accessible SST provides a valuable advantage over competitors not offering SST alternatives. Understanding the types of intense or immediate needs customers may experience should help managers effectively design and position their SSTs relative to competitors.

The second and largest major category for satisfying incidents is the relative advantage that customers perceive they get from using an SST. These benefits received are typically viewed by customers in comparison with interpersonal service delivery alternatives. Although these advantages (e.g., time, ease of use, access) can be emphasized by companies to increase SST usage and generate satisfaction, customer perceptions of SST benefits may also be an indicator of the failure of service providers to satisfy customers through traditional forms of interpersonal service delivery. This is highlighted in the incidents in which respondents discussed using SST options to avoid interacting with service employees. Although this sentiment was expressed by a relatively small percentage of the sample, it suggests that some consumers believe they are more effective at producing the service than an employee who has (hopefully) been trained to deliver the service. That some customers perceive frontline employees as a nuisance to be avoided highlights the hiring and training problems that some service organizations may currently be experiencing. These problems may lead to less loyalty and increased switching behavior, especially if higher-quality personal service is offered by competing firms. Our findings are consistent with general perceptions of declining service that have been documented by national studies that measure customer satisfaction (Grant 1998). Self-service technologies may provide a way for customers to avoid this declining service and produce and consume on their own, at their own convenience.

The third major satisfactory category, "did its job," consists of many incidents that simply described the technology doing what it was intended to do. Many consumers are still fascinated with the capability of various SSTs and seem pleasantly surprised when the SSTs perform successfully, because many SSTs are still in their infancy. Therefore, the novelty of the technology and its ability to perform these services may be satisfying. After the novelty wears off, it is possible that expectations will increase, thereby making status quo interactions with SSTs less satisfying to consumers. This may lead to more competition among firms with similar SSTs and provide a greater incentive for firms to improve technology interfaces and SST capabilities and expand SST service offerings for customers.

The first and largest dissatisfactory group, technology failure, includes situations in which customers are prevented from using the service. The difficulty of implementing effective service recovery efforts in SST contexts is especially evident during technology failures. Customers who are confronted with a technology failure have several options, none of which is beneficial to the service firm. First, customers may be driven to switch service providers. A second option is to revert to the interpersonal delivery alternative. This transfer from technology-based transactions to interpersonal encounters may overload service firm employees or increase waiting times for other customers. In addition, interpersonal transactions are generally more expensive for firms than transactions conducted through an SST. Finally, consumers may simply decide not to use the service or to use it at a later date. This would either eliminate potential revenue or at the very least delay revenue to a later time period. This source of dissatisfaction indicates the importance of regular maintenance for SSTs. Just as continual training and investment in frontline employees helps improve service delivery, SSTs must receive ongoing maintenance to ensure continued effectiveness.

In this study, many of the dissatisfying incidents were caused by process failures. Although the technology is working properly, in these incidents there is a breakdown at some point after the SST encounter has occurred but before the service consumption has been completed. The process failure category highlights the ability of the addition of technology to improve service delivery only to the extent that the rest of the service process is implemented effectively. The danger of this type of failure is that the customer assumes that the transaction will be completed as expected, which may cause significant complications when the failure becomes apparent.

The dissatisfying incidents also suggest that poor design is a significant problem for both the technology interface and other aspects of the service process. Technological tools, specifically SSTs, are used to their full advantage only when they are designed with customer needs in mind and fully integrated into the design of the overall service. One way to reduce these types of failures is to include customers in the design of the SST and the corresponding service process. Merely integrating technology without regard to customer needs or integrating technology into a faulty system is a recipe for disaster.

The last dissatisfactory category, customer-driven failure, indicates that customers are willing to take some of the blame when dissatisfying encounters with SSTs occur. This suggests that users of SSTs are aware that their interactions with the SST influence the nature of the outcome they experience. It is in a firm's best interest to understand what mistakes customers make that may lead to these dissatisfying outcomes. This allows steps to be taken to help customers help themselves. Continually acquiring customer feedback and providing extensive SST training are two ways to limit the impact of customer-driven failures.

\section{SST Versus Interpersonal Encounter Satisfaction}

Another goal of this project, reflected in the second research question, is to compare the categories found for SST service encounters with the sources of dis/satisfaction found in interpersonal service encounters. The three main sources of dis/satisfaction with interpersonal service encounters mentioned previously are (1) response to service delivery failure, (2) response to customer needs, and (3) unprompted or unsolicited actions (Bitner, Booms, and Tetreault 1990). These can be considered more broadly as the following three 
drivers of memorable satisfying incidents: excellent service recovery, customization/flexibility, and spontaneous delight, respectively. These categories differ greatly from those found for service encounters involving SSTs.

Research examining interpersonal service encounters clearly demonstrates that successful recovery in the wake of a service delivery failure is satisfying to customers, whereas a failure to recover is highly dissatisfying (Tax, Brown, and Chandrashekaran 1998). In our research, recovery did not emerge as a source of satisfaction or dissatisfaction. One possible reason is that recovery rarely occurs in SST contexts, because most firms have not figured out how to recover effectively. Therefore, none of our respondents mentioned an act of recovery when describing a satisfying incident. However, failures were the focus of all of dissatisfying SST encounters. Therefore, at some level, each of these failures represents a missed opportunity for service recovery. The results suggest that firms that employ SSTs could do a great deal more in the area of service recovery and should take steps to ensure that customers have the knowledge and motivation to use technology to recover without help when possible.

In addition to service recovery, the interpersonal encounter research highlights how dis/satisfaction is associated with service employees' ability to customize the service. Customers appreciate service providers' ability to adapt and adjust elements of the service in real time during service delivery to meet consumers' needs and are dissatisfied when employees cannot do so (Bettencourt and Gwinner 1996). In our research, customization did not emerge as a source of satisfaction for SSTs per se. However, several of the satisfying incidents focused on benefits of using an SST that are aspects of service customization (i.e., can get the service "when I want" and "where I want"). In addition, some of the design problems associated with dissatisfying incidents could be viewed as a lack of customization. Therefore, although the theme of customization is not as pronounced in our results, we can see hints of it in the responses. We anticipate that the impact of customization on satisfaction will be much stronger in the future, because we can readily realize the great possibilities of customization when we consider Internet retailers such as Amazon.com, which allows customers to search for books (among other things) how they want, get the type of information (e.g., reviews, excerpts) they desire, and even choose how they pay (e.g., online versus over the telephone), all of which are forms of customization. To compete effectively in the future, firms will need to continue to find innovative ways to customize SSTs to meet the changing needs and preferences of customers.

The third driver of dis/satisfaction that emerges in interpersonal encounter research involves unsolicited actions on the part of an employee. In a positive sense, spontaneous delight occurs when an employee provides a customer with an unexpectedly pleasing experience (Oliver, Rust, and Varki 1997). In the context of SSTs, instead of experiencing spontaneous delight, customers appear to be highly dissatisfied with unexpected technical failures. On a more positive note, the "did its job" category could be interpreted as an example of spontaneous delight in that this group of customers was amazed at what the SST could do. Although this source of satisfaction is likely to be fleeting as customers become more sophisticated users of SSTs, SSTs have the potential to delight a broad spectrum of customers. Our results show that being able to save money or get perks can be satisfying for customers. We also find leading-edge companies, such as Cisco Systems, succeeding at delighting their customers. Cisco has developed an award-winning expert system that aids customers in problem identification and resolution, which results in customers being amazed at what they can accomplish by themselves.

With the advent of new technology and the evolution of SSTs, SSTs are likely to be developed that have the capability to mimic and/or surpass the positive aspects of interpersonal encounters in the future. For example, it is not difficult to imagine a time when companies will have systems in place that not only monitor if and how an SST is functioning but also prevent failures before they happen and/or provide realtime service recovery for customers as they interact with an SST. This is similar in many respects to what firms such as Caterpillar and Xerox already do in anticipating equipment breakdowns through remote monitoring systems. The potential of customization for Internet-based SSTs has already been demonstrated clearly by a handful of leading firms. Given that technology enables firms to know more about their customers (i.e., their preferences and past behavior), it is expected that mass customization will become increasingly common. It also creates an endless array of possibilities for delighting customers in highly customized, unique ways. For example, given their knowledge of customers, firms could send unsolicited, personally relevant information to customers or provide rewards (e.g., discounts) that would be highly valued by a particular customer. A current example of this is Amazon.com, which notifies customers when a new book is available in a preferred book category.

\section{Consumer Reactions to the SST Experience}

The third research question we investigated was the nature of relationships between the encounter and measures of attributions, complaining, and future behaviors such as repeat purchase and word of mouth. Our results indicate that users of SSTs are most likely to attribute the outcome of the encounter to technology, and more respondents do so for a dissatisfying than a satisfying encounter. Only a small percentage of respondents cited themselves as responsible for the outcome, though they were more likely to do so for satisfying versus dissatisfying incidents. In addition, the outcome was attributed equally to both technology and the user in significantly more satisfying encounters than in dissatisfying encounters. Thus, although respondents produce the service themselves, few translate their involvement into selfblame when things go wrong. This finding further emphasizes the need to prevent service failure and educate customers on their roles, because they are unlikely to share in the blame if the service fails.

The percentage of customers willing to complain in response to a dissatisfying encounter with an SST appears to be somewhat higher for some of the dissatisfaction categories than has been documented elsewhere in the literature (see Heskett, Sasser, and Schlesinger 1997; Technical Assistance Research Programs Institute 1986). In three of the five 
dissatisfactory categories, at least $50 \%$ of the customers complained. Closely examining complaint rates across dissatisfactory categories provides insight into the high complaint rates in SST encounters.

The two categories resulting in the highest levels of complaining are technology failures and process failures. Technology failures, such as machines being out of order, typically force consumers to complain in order to conduct the transaction. In process failures, the actual SST encounter worked as expected, but the underlying process failed at a later point. Process failures are especially troubling, because the consumer has completed the SST interaction and expects the transaction to be processed successfully. However, when the encounter is not completed, the customer must complain to resolve the situation (e.g., items are purchased through the Internet but are never received). Service design problems also resulted in complaints from a majority of the respondents. Customers may perceive these service design problems to be more easily fixed and therefore believe that complaining to the firm may result in service design changes.

In addition, SST failures are frequently more objective and obvious than failures in an interpersonal service encounter. In interpersonal encounters, dissatisfaction may be ambiguous; for example, a customer may have an unpleasant experience with the provider, but the service is still provided. In technologically based encounters, failures are often more apparent, which results in little ambiguity regarding whether a failure actually occurred.

As is expected, when customers perceive that they are at fault for the encounter failure (customer-driven failures), complaint rates are relatively low. Encounters in which technology design problems were cited as reasons for the dissatisfactory experience also generated low complaint rates. It appears that consumers are unhappy with the way the technological interface has been designed but, perhaps because of the perceived inflexibility, believe that complaining will not result in any changes in the design of the technology. Furthermore, they are typically able to complete the transaction and therefore are not forced to complain as in other categories.

The beneficial implications of higher complaint rates are important to consider. First, customer complaints enable firms to adapt SST systems proactively to prevent future failures. Second, complaining customers provide firms the opportunity to prevent service switching by customers who are unhappy with their SST experience. When complaints are made, it is important for firms to address the issues quickly to prevent this service switching (Tax and Brown 1998; Tax, Brown, and Chandrashekaran 1998).

Overall, the level of complaining is rather high, especially considering that in many cases it is difficult to find an avenue to complain when a problem arises. Results show that complaining often was done interpersonally. Note that when a failure occurred, $83 \%$ of the respondents who complained contacted the firm either in person or over the telephone. In these cases, the value of using an SST is lost for both the customer and the firm. A failure necessitates that a customer service representative handle an additional customer interaction that should have been successfully accomplished by the SST. Relatively few customers (12\%) use electronic approaches to voice their displeasure with the SST or the service experience. It is critical for service firms to provide an array of avenues (both interpersonal and technological) for SST users to contact them easily and quickly to lodge a complaint or suggestion.

The type of the failure differentially affects the future behavior of customers. Even after dissatisfactory experiences, some respondents indicated that positive future behaviors were likely. Respondents were more likely to use the same company's SST in the future and recommend it to a friend when there had been a technology failure than when other types of failures occurred. There seems to be some understanding that these problems are likely to occur at least on occasion, and customers are more forgiving in these situations. Respondents were also more likely to exhibit positive future behaviors when they had played a role in creating a negative outcome than when there was a mistake in the process or some type of technology or service design problem. Given that design problems may be perceived as permanent and more likely to continue to influence the outcome of the encounter, we find more customers who are not recommending the company's SST and not using it again when they view design problems as the reason for the poor outcome. This indicates that these types of failures may be particularly important for service firms to avoid because of the serious consequences they have for customer loyalty.

\section{Conclusions and Future Research Directions}

Technology has become an integral part of the marketplace. Customers are increasingly given the option or are being asked to provide services for themselves through the use of SSTs. It is important for providers of SSTs to understand how customers evaluate SSTs so that the firms can improve them. In this research, we have identified several factors that appear to influence dis/satisfaction with technology-based service encounters. These factors can therefore provide insight for firms that currently offer or are planning to offer an SST as an alternative method of service delivery.

Although the Web-based sample was appropriate for this study and provides substantial benefits, the sample presents limitations that should be addressed in further research. It is possible that the participants in the online survey have a generally more positive attitude toward SSTs than the general population. This bias could prevent additional categories from being identified. In addition, these respondents may have different reactions to the SST encounter than a sample that included less experienced SST users. For example, respondents with less SST experience may be more likely to blame themselves for a failure or less likely to complain about a failure. However, the large sample of more than 800 respondents may help limit the effects of this bias. In addition, although a nationwide sample was collected, the respondents were not randomly selected. They were reached through panel membership in an Internet-based marketing research firm, which limits the generalizability of the findings.

There are several important avenues for further research in this area. Although in this research the focus was end 
users of SSTs, the fastest growing segment of technologically related transactions is in the business-to-business realm (Hof 1999). Because SSTs are also increasingly being introduced in business-to-business contexts, their usage should be examined to determine what drives dis/satisfaction for business customers. In addition, the way SSTs can help or hinder the development of alliances between business partners could be investigated.

A contribution of the current study is its exploration of a wide range of SSTs, as suggested in Figure 1. Given the design of our study and the current level of usage for many SSTs, we did not attempt to draw explicit comparisons across the different types of SSTs represented by the matrix. This is another avenue for further research. For example, are there inherent differences in how customers prefer to use and how they react to SSTs designed for customer service purposes versus those designed to facilitate transactions? Similarly, are there underlying differences in how customers respond to telephone-based versus Internet-based SSTs? Whereas our study was designed to examine the range of SSTs to assess underlying similarities, further research could be designed specifically to allow comparison of the cells within the matrix.

Given the proliferation of SSTs being introduced, it is also important to understand the factors that influence adoption of technology-based service delivery options. Research on customer participation suggests that role clarity, motivation, and customer ability are important factors affecting customer participation in service delivery (Bowen 1986; Schneider and Bowen 1995). Research could examine what motivates people to use an SST, how they go about learning their role as it relates to interacting with an SST, and what factors limit perceived ability to interact with SSTs. Providing customers with an opportunity to learn their role is especially important given that service employees usually are not present to educate or train customers in SST settings. Understanding these factors will help managers gain insight into how to get customers to use currently underused SSTs as well as to adopt new SST innovations.

Finally, additional research is needed to examine the implications that arise from the inherent characteristics of SSTs. For example, how should a firm go about developing trust with customers when there is an absence of human contact? How does the lack of human contact affect loyalty, and what are the determinants of service loyalty regarding SSTs? Is it easier for customers to switch, and if so, how can loyalty be built into these situations? Last, the difficulty associated with service recovery should be explored. Specifically, what does service recovery mean and how can it be implemented in the SST context? Greater insight into these and other issues will enable companies to make the most effective use of their SSTs.

Effective management of SST delivery options can be an excellent means of creating a competitive advantage. This research represents a first step in better understanding the overall evolution of SSTs. Currently, SSTs generally provide alternative service delivery channels, yet additional development could meld the benefits of technologically based encounters with the benefits of interpersonal encounters, such as adaptability. When these delivery options are better understood, effective management of these channels may increase profitability and success in the increasingly competitive marketplace.

\section{REFERENCES}

Anderson, Eugene W. and Claes Fornell (1994), "A Customer Satisfaction Research Prospectus," in Service Quality: New Directions in Theory and Practice, Roland T. Rust and Richard L. Oliver, eds. Thousand Oaks, CA: Sage Publications, 241-68.

Bateson, J.E.G. (1985), "Self-Service Consumer: An Exploratory Study," Journal of Retailing, 61 (Fall), 49-76.

Bettencourt, Lance and Kevin Gwinner (1996), "Customization of the Service Experience: The Role of the Frontline Employee," International Journal in Services Industry Management, 7 (2), 2-20.

Bitner, Mary Jo (1990), "Evaluating Service Encounters: The Effects of Physical Surroundings And Employee Responses," Journal of Marketing, 54 (April), 69-82.

—, Bernard H. Booms, and Lois A. Mohr (1994), "Critical Service Encounters: The Employee's View," Journal of Marketing, 58 (October), 95-106.

— - , and Mary Stanfield Tetreault (1990), "The Service Encounter: Diagnosing Favorable and Unfavorable Incidents," Journal of Marketing, 54 (January), 71-84.

- Stephen W. Brown, and Matthew L. Meuter (2000), "Technology Infusion in Service Encounters," Journal of the Academy of Marketing Science, 28 (1), 138-49.

Bowen, David E. (1986), "Managing Customers as Human Resources in Service Organizations," Human Resource Management, 25 (Fall), 371-83.

Clemmer, Elizabeth C. and Benjamin Schneider (1996), "Fair Service," in Advances in Services Marketing and Management, Vol. 5, Teresa A. Swartz, David E. Bowen, and Stephen W. Brown, eds. Greenwich, CT: JAI Press, 109-126.

Copas, Ernestine M. (1984), "Critical Requirements for Cooperating Teachers," Journal of Teacher Education, 35 (6), 49-54.

Dabholkar, Pratibha A. (1992), "Role of Affect and Need for Interaction in On-Site Service Encounters," in Advances in Consumer Research, Vol. 19, John F. Sherry and Brian Sternthal, eds. Provo, UT: Association for Consumer Research, 563-69.

(1994), "Technology-Based Service Delivery: A Classification Scheme for Developing Marketing Strategies," in Advances in Services Marketing and Management, Vol. 3, Teresa A. Swartz, David E. Bowen, and Stephen W. Brown, eds. Greenwich, CT: JAI Press, 241-71.

- (1996), "Consumer Evaluations in New Technology-Based Self-Service Options: An Investigation of Alternative Models of Service Quality," International Journal of Research in Marketing, 13 (1), 29-51.

Darian, Jean C. (1987), "In-Home Shopping: Are There Consumer Segments?" Journal of Retailing, 63 (2), 163-86.

Eastlick, Mary Ann (1996), "Consumer Intention to Adopt Interactive Teleshopping," Marketing Science Institute Working Paper No. 96-113. Cambridge, MA: Marketing Science Institute.

Fischer, Eileen, Brenda Gainer, and Julia Bristor (1997), "The Sex of the Service Provider: Does It Influence Perceptions of Service Quality?" Journal of Retailing, 73 (3), 361-82.

Fisk, Raymond P., Stephen W. Brown, and Mary Jo Bitner (1993), "Tracking the Evolution of the Services Marketing Literature," Journal of Retailing, 69 (1), 61-103.

Flanagan, John C. (1954), "The Critical Incident Technique," Psychological Bulletin, 51 (July), 327-57.

Folkes, Valerie S., Susan Koletsky, and John L. Graham (1987), “A Field Study of Causal Inferences and Consumer Reaction: The View from the Airport," Journal of Consumer Research, 13 (March), 534-39. 
Gibson, Richard (1999), "Machine Takes Orders in Test by McDonald's," Wall Street Journal, (August 11), B1.

Goodwin, Cathy (1996), "Communality as a Dimension of Service Relationships," Journal of Consumer Psychology, 5 (4), 387-415.

— and Dwayne D. Gremler (1996), "Friendship Over the Counter: How Social Aspects of Service Encounters Influence Consumer Service Loyalty," in Advances in Services Marketing and Management, Vol. 5, Teresa A. Swartz, David E. Bowen, and Stephen W. Brown, eds. Greenwich, CT: JAI Press, 247-82.

Grant, Linda (1998), "Your Customers Are Telling the Truth," Fortune, (February 18), 164.

Greco, Alan J. and D. Michael Fields (1991), "Profiling Early Triers of Service Innovations: A Look at Interaction Home Video Ordering Services," Journal of Services Marketing, 5 (3), $19-26$.

Grove, Stephen J. and Raymond P Fisk (1997), "The Impact of Other Customers on Service Experiences: A Critical Incident Examination of 'Getting Along,", Journal of Retailing, 73 (1), 217-24.

Hartline, Michael D. and O.C. Ferrell (1996) "The Management of Customer-Contact Service Employees: An Empirical Investigation," Journal of Marketing, 60 (October), 52-70.

Heskett, James L., W. Earl Sasser Jr., and Leonard A. Schlesinger (1997), The Service Profit Chain. New York: The Free Press.

Hof, Robert D. (1999), "A New Era of Bright Hopes and Terrible Fears," BusinessWeek, (October 4), 84-98.

Hoffman, K. Douglas, Scott W. Kelley, and Holly M. Rotalsky (1995), "Tracking Service Failures and Employee Recovery Efforts," Journal of Services Marketing, 9 (2), 49-61.

Hubbert, Amy R. (1995), "Customer Co-creation of Service Outcomes: Effects of Locus of Causality Attributions," doctoral dissertation, Chemistry Department, Arizona State University.

Iacobucci, Dawn, Amy Ostrom, and Kent Grayson (1995), "Distinguishing Service Quality and Customer Satisfaction: The Voice of the Consumer," Journal of Consumer Psychology, 4 (3), 277-303.

Keaveney, Susan M. (1995), "Customer Switching Behavior in Service Industries: An Exploratory Study," Journal of Marketing, 59 (April), 71-82.

Langeard, Eric, John Bateson, Christopher H. Lovelock, and Pierre Eiglier (1981), "Services Marketing: New Insights from Consumers and Managers," Report No. 81-104. Cambridge, MA: Marketing Science Institute.

Lathan, Gary and Lise M. Saari (1984), "Do People Do What They Say? Further Studies on the Situational Interview," Journal of Applied Psychology, 69 (4), 569-73.

Lawrence, Philip and John Karr (1996), "Technology Spendingand Alliances: New Highs in Financial Services Firms," Journal of Retail Banking Services, 17 (3), 45-52.

Mano, Haim and Richard L. Oliver (1993), "Assessing the Dimensionality and Structure of Consumption Experience: Evaluation, Feeling, and Satisfaction," Journal of Consumer Research, 20 (December), 451-66.

Martin, Charles L. and Charles A. Pranter (1989), "Compatibility Management: Customer-to-Customer Relationships in Service Environments," Journal of Services Marketing, 3 (Summer), $6-15$.

Merrill, Ann (1999), "Rainbow's Version of Fast Food," Star Tribune (Minneapolis), (August 12), D1.

Meuter, Matthew L. and Mary Jo Bitner (1998), "Self-Service Technologies: Extending Service Frameworks and Identifying Issues for Research," in AMA Winter Educator's Conference Proceedings: Marketing Theory and Applications, Vol. 9, Dhruv Grewal and Connie Pechmann, eds. Chicago: American Marketing Association, 12-19.

Mills, Peter K., Richard Chase, and N. Margulies (1983), "Motivating the Client/Employee System as a Service Production Strategy," Academy of Management Review, 8 (2), 301-310.
Mohr, Lois A. and Mary Jo Bitner (1995), "Process Factors in Service Delivery: What Employee Effort Means to Customers," in Advances in Service Marketing and Management, Vol. 4, Teresa A. Swartz, David E. Bowen, and Stephen W. Brown, eds. Greenwich, CT: JAI Press, 91-117.

Oliver, Richard L. (1993), "Cognitive, Affective, and Attribute Bases of the Satisfaction Response," Journal of Consumer Research, 20 (December), 418-30.

(1997), Satisfaction: A Behavioral Perspective on the Consumer. New York: McGraw-Hill Companies, Inc.

_, Roland T. Rust, and Sajeev Varki (1997), "Customer Delight: Foundations, Findings, and Managerial Insight," Journal of Retailing, 73 (3), 311-36.

Parasuraman, A. (1996), "Understanding and Leveraging the Role of Customer Service in External, Interactive and Internal Marketing," paper presented at Frontiers in Services Conference, Nashville, TN (October).

(1998), "Customers' Comfort Level with TechnologyBased Services: An Empirical Study," paper presented at AMA Winter Educator's Conference, Austin, TX (February 21-24).

Perreault, William D., Jr., and Laurence E. Leigh (1989), "Reliability of Nominal Data Based on Qualitative Judgments," Journal of Marketing Research, 26 (May), 135-48.

Price, Linda L., Eric J. Arnould, and Sheila L. Deibler (1995), "Consumers' Emotional Responses to Service Encounters," International Journal of Service Industry Management, 6 (3), 34-63.

and Patrick Tierney (1995), "Going to Extremes: Managing Service Encounters and Assessing Provider Performance," Journal of Marketing, 59 (April), 83-97.

Quinn, James Brian (1996), “The Productivity Paradox Is False: Information Technology Improves Service Performance," in Advances in Services Marketing and Management, Vol. 5, Teresa A. Swartz, David E. Bowen, and Stephen W. Brown, eds. Greenwich, CT: JAI Press, 71-84.

Rafaeli, Anat (1993), "Dress and Behavior of Customer Contact Employees: A Framework for Analysis," in Advances in Service Marketing and Management, Vol. 4, Teresa A. Swartz, David E. Bowen, and Stephen W. Brown, eds. Greenwich, CT: JAI Press, 175-211.

Raub, Annalyse Callahan (1981), "Correlates of Computer Anxiety in College Students," doctoral dissertation, Chemistry Department, University of Pennsylvania.

Rayport, Jeffrey F. and John J. Sviokla (1994), "Managing in the Marketspace," Harvard Business Review, 72 (November/ December), 2-11.

and - (1995), "Exploiting the Virtual Value Chain," Harvard Business Review, 73 (November/December), 14-24.

Reichheld, F.F. and W.E. Sasser Jr. (1990), “Zero Defections: Quality Comes to Services," Harvard Business Review, 68 (September/October), 105-111.

Schneider, Benjamin and David E. Bowen (1995), Winning the Service Game. Boston: Harvard Business School Press.

Smith, Amy K. and Ruth N. Bolton (1998), "An Experimental Investigation of Customer Reactions to Service Failure and Recovery Encounters," Journal of Service Research, 1 (1), 65-81.

Solomon, Michael R., Carol F. Surprenant, John A. Czepiel, and Evelyn G. Gutman (1985), "A Role Theory Perspective on Dyadic Interactions," Journal of Marketing, 49 (Winter), 99-111.

Surprenant, Carol F. and Michael R. Solomon (1987), "Predictability and Personalization in the Service Encounter," Journal of Marketing, 51 (April), 73-80.

Tax, Stephen S. and Stephen W. Brown (1998), "Recovering and Learning from Service Failure," Sloan Management Review, 40 (1), 75-88.

, and Murali Chandrashekaran (1998), "Customer Evaluations of Service Complaint Experiences: Implications for Relationship Marketing," Journal of Marketing, 62 (April), 60-76. 
Technical Assistance Research Programs Institute (1986), Consumer Complaint Handling in America: An Update Study, Part II. Washington, DC: U.S. Office of Consumer Affairs.

White, Frank M. and Edwin A. Locke (1981), "Perceived Determinants of High and Low Productivity in Three Occupational Groups: A Critical Incident Study," Journal of Management Studies, 18 (4), 375-87.
Zeithaml, Valarie (1981), "How Consumer Evaluation Processes Differ Between Goods and Services," in Marketing Services, James H. Donnelly and William R. George, eds. Chicago: American Marketing Association, 186-89. and Mary C. Gilly (1987), "Characteristics Affecting the Acceptance of Retailing Technologies: A Comparison of Elderly and Nonelderly Consumers," Journal of Retailing, 63 (1), 49-68. 